\title{
Differences in quality parameters between types of commercial tea from Argentina
}

\author{
THEA, ANA E. ${ }^{a^{*}}$, LLORET, MARÍA A. ${ }^{a}$, BRUMOVSKY, LUIS A. ${ }^{a}$, AND \\ SCHMALKO, MIGUEL E. ${ }^{a}$

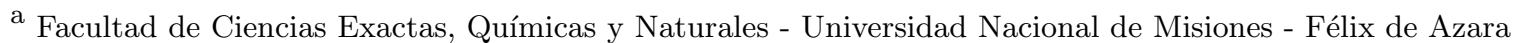 \\ 1552, Posadas (3300), Misiones, Argentina. \\ ${ }^{*}$ Corresponding author \\ anitothea@hotmail.com \\ TEL: +543764428776 \\ FAX: +543764425414
}

Received: 7 March 2012; Published online: 18 October 2012

\begin{abstract}
To determine differences in quality parameters between different types of tea elaborated in Argentina, water extract, crude fibre, caffeine, total polyphenol content, antioxidant activity, sorption isotherms and colour parameters (L, a, b) were determined. Fifty-one industrial samples of commercially available teas including green tea, semifermented tea, black tea and black tea sub-product (BTSP) were used for this study.

Water extract contents were significantly higher in black tea and green tea $(40.3 \%$ and $40.7 \% \mathrm{w} / \mathrm{w}$, respectively), while semifermented tea and BTSP showed higher levels of crude fibre $(22.3 \%$ and $20.4 \%$ $\mathrm{w} / \mathrm{w}$, respectively). Caffeine contents of black teas $(2.7 \% \mathrm{w} / \mathrm{w})$ were significantly higher than in the other types of tea. Green teas revealed the highest concentrations of phenolic compounds and the major antioxidant activities (14.9 g GAE/100g dm and $30.0 \mathrm{~g} \mathrm{AAE} / 100 \mathrm{~g} \mathrm{dm}$, respectively). The results also highlighted significant differences $(\mathrm{p}<0.05)$ in colour values between the different types of tea.
\end{abstract}

Keywords: Camellia sinensis; black tea; green tea; semifermented tea; quality parameters.

\section{Introduction}

The tea plant (Camellia sinensis (L) O. Kuntze) is cultivated all over the world and each zone of growing produces a product with differential qualities as a result of climate and edaphic site conditions, farming techniques and industrialization (Parra, 2007; Saito et al., 2007).

Teas from the genus Camellia can be divided into three categories based on the tea manufacturing (fermentation) process: green tea (unfermented), oolong tea (partially fermented), and black tea (fully fermented) (Kim, Goodner, Park, Choi, \& Talcott, 2011).

Copyright (C)2012 ISEKI-Food Association (IFA)
The major producers of $C$. sinensisare China, India and Sri Lanka, but the cultivation of tea on a large scale has spread subsequently to many other parts of Asia, Africa and South America (Saito et al., 2007; Parra, 2007).

Tea was firstly introduced to Argentina in 1923 with seeds brought from Georgia. Tea production remained a minor activity up until 1951 when the Argentine government banned imported tea. This increased the demand for local tea and more farmers began to plant it, so that at the end of the decade Argentina was able to export tea (Parra, 2007; Prat Kricun \& De Bernardi, 2002). Argentinean tea production has 
been steadily increasing since the $1960 \mathrm{~s}$, from 6,486 tons in 1961 to 73,425 tons in 2009 ("FAO Statistics Division," 2011).

The production area is located in the northeast part of the country, in the provinces of Misiones and Corrientes, the southernmost region in the world. Argentinean tea production includes only an average of $3 \%$ of green tea and semifermented tea, and the rest corresponds to black tea and black tea sub-product (BTSP) which is mainly sold to foreign markets, where the United States and Chile are predominant destinations (Parra, 2007). BTSP is obtained during the sorting process, where tea is separated from fibrous residue which is of no commercial value as a grade. BTSP is an "off grade" tea primarily used in the production of instant tea; for blending with superior grades and decreasing the price of the final product; and most of it ends up in iced tea beverages popular in the United States (Prat Kricun \& De Bernardi, 2002).

The quality of tea is dependent, in the first instance, on the chemical composition of the harvested shoots, and in the second instance, on the way in which they are handled, processed and stored (Yao et al., 2005). Many factors, such as geographical location, cultivar species, season, age of the leaves, climate and horticultural practices (soil, water, minerals, fertilizers) may influence the chemical composition of tea leaves (Saito et al., 2007; Jayasekera, Molan, Garg, \& Moughan, 2011; von Staszewski, Pilosof, \& Jagus, 2011; Kerio, Wachira, Wanyoko, \& Rotich, 2012). Because of these factors, the chemical characterization of teas from different origins is very important considering that these studies are currently scarce (Saito et al., 2007). The moisture content, water extract, crude fibre content, total polyphenol content and antioxidant capacity have long been regarded as important international standards for quality control of tea (ISO 3720, 2011; Yao et al., 2006; Anesini, Ferraro, \& Filip, 2008; Smiechowska \& Dmowski, 2006; Ravichandran, 2004; Jayasekera et al., 2011; von Staszewski et al., 2011).

Moisture content is one of the principal quality parameters in foodstuffs because it is related to its stability. Each food has its maximum value of moisture content. This limit is determined through the adsorption isotherms, because there is no microbial growth at water activity values lower than 0.6 .

Water extract and crude fibre contents are related to the age of the leaves. Younger leaves have high water extract and low fibre content values (related to a high quality product) (Smiechowska \& Dmowski, 2006).

Total polyphenol content and antioxidant capacity depend on the leaf age and the manufacturing process (particularly on the degree of fermentation) and are directly correlated to the quality of the final product (Lin, Lin, Liang, Lin-Shiau, \& Juan, 1998). Caffeine is considered an important quality parameter of tea, not only for its contribution to tea flavour but also as an indicator of tea leaf maturity (Yao et al., 2006). It is considered that the finest teas are made from young tea shoots containing the highest levels of methylxanthines and phenolic compounds.

During the fermentation process in black tea and semifermented tea manufacture, enzymatic oxidation of polyphenols takes place, leading to formation of coloured compounds. Depending on the extent of fermentation and the concentration of phenolic compounds in the leaves, the colour of tea will vary accordingly. Thus, colour parameter analysis is useful to characterize the different types of tea and to investigate their quality.

The aim of this research was to evaluate the quality parameters of different types of tea elaborated in Argentina and to determine the parameters to differentiate between them. Water extract, crude fibre, caffeine, total polyphenol, antioxidant capacity, sorption isotherms and colour parameters were studied.

\section{Materials and Methods}

\subsection{Tea Samples}

Fifty industrial samples of commercially available teas, including BTSP $(n=11)$, green tea $(n=11)$ and black tea $(n=28)$ were used for this study. Tea samples were obtained from different factories located in the provinces of Misiones and Corrientes, Argentina. One semifermented tea sample, provided by the only producer in Argentina, was also used for comparison.

The BTSP, black and green teas used in the sorp- 
tion isotherm experiments were provided by the same manufacturer and they were obtained from the same starting material.

\subsection{Caffeine}

For the determination of the caffeine content, caffeine (Sigma Ultra, Argentina) and methanol (HPLC grade, Merck, Argentina) were used. Caffeine was determined by HPLC using the technique reported in ISO 10727 (2002).

\subsection{Water extract}

The water extract content was determined according to the method described in ISO 9768 (1994).

\subsection{Crude fibre}

The crude fibre content was determined by the general method (ISO 15598, 1999) with modification as detailed below. First, a sample of tea $(0.5 \mathrm{~g})$ was boiled in $50 \mathrm{~mL}$ of $0.255 \mathrm{~N}$ sulfuric acid solution for $30 \mathrm{~min}$, the mixture obtained was centrifuged at $377 \times \mathrm{g}$ for $5 \mathrm{~min}$, then the insoluble residue was filtered and washed. The obtained substance was subsequently boiled in $0.313 \mathrm{M}$ sodium hydroxide solution for $30 \mathrm{~min}$, the mixture was centrifuged, filtered and washed. The residue obtained was dried for $2 \mathrm{~h}$ in the oven at $103 \pm 2^{\circ} \mathrm{C}$. Finally, mass loss was determined after ashing at $525 \pm 25^{\circ} \mathrm{C}$.

\subsection{Colour}

The colour values (L, a, b) of tea samples were measured with a Hunter Lab D25-9 colorimeter (Hunter Associates Laboratory, Reston, Virginia, USA). Each colour value was measured three times.

\subsection{Total polyphenols content and antioxidant activity}

For the determination of total polyphenol content (TPC), Folin-Ciocalteu's reagent (Fluka,
Argentina), gallic acid (MP Biomedicals, Argentina), methanol (Merck, Argentina) and anhydrous sodium carbonate (Anedra, Argentina) were used. For the determination of the antioxidant activity (AOA), 1,1-diphenyl-1picrylhydrazyl (Sigma, Argentina) and ascorbic acid (Sigma Ultra, Argentina) were employed. The extraction of polyphenols was done according to the method described in ISO 14502-1 (E) (2004). Briefly, $0.200 \pm 0.001 \mathrm{~g}$ of each sample was weighed in an extraction tube and $5 \mathrm{~mL}$ of $70 \%$ methanol solution was added. The extract was mixed and heated at $70^{\circ} \mathrm{C}$ for $10 \mathrm{~min}$. Then, the extract was centrifuged for $10 \mathrm{~min}$. The supernatant was reserved in a graduated tube. The extraction step was repeated twice. The combined supernatants liquors were readjusted to a fixed volume $(10 \mathrm{~mL})$ with $70 \%$ methanol. One millilitre of the extract was diluted with water to $100 \mathrm{~mL}$.

The TPC was determined by spectrophotometry, using Folin-Ciocalteau's reagent and the results were expressed as gallic acid equivalents (GAE), according to the method described in ISO 145021 (E) (2004). Standard concentrations of gallic acid between 0 and $50 \mu \mathrm{g} / \mathrm{mL}$ were used to prepare the calibration curve.

The AOA was determined by the 1, 1-diphenyl1-picrylhydrazyl (DPPH) free radical scavenging assay using ascorbic acid as standard and the results were expressed as ascorbic acid equivalents (AAE) (Hartwig, Brumovsky, Fretes, \& Sánchez Boado, 2012). The DPPH assay has been widely used to test the ability of compounds to act as free radical scavengers or hydrogen donors and to evaluate the AOA of foods and plant extracts. The assay detects the scavenging of free radicals by samples through the scavenging activity of the stable DPPH free radical (Jayasekera et al., 2011). A volume of $1 \mathrm{~mL}$ of each tea sample extract was diluted with water (1:25 for BTSP, black and semifermented tea and 1:40 for green tea). Then $100 \mu \mathrm{L}$ volumes of the diluted sample extract were mixed with $3 \mathrm{~mL}$ of a $100 \mu \mathrm{M} \mathrm{DPPH}$ solution in absolute methanol. The mixture was kept for $2 \mathrm{~h}$ at $37^{\circ} \mathrm{C}$ in darkness, and then the absorbance was measured at $517 \mathrm{~nm}$. Standard concentrations of ascorbic acid between 0 and 22 $\mu \mathrm{g} / \mathrm{L}$ were used to prepare the calibration curve. 


\subsection{Adsorption isotherms}

Different levels of water activity $\left(\mathrm{a}_{w}\right)$ were generated using saturated salt solutions placed at the bottom of closed desiccators. The desiccators were maintained in an oven at the experimental temperature $\left(25^{\circ} \mathrm{C}\right)$. In each desiccator, nine flasks (three materials, each with three replicates) containing the samples (approximately 3 g) were placed on a grid over the salt solutions. The following salts were used: $\mathrm{LiCl}\left(\mathrm{a}_{w}: 0.113\right)$, $\left.\mathrm{MgCl}_{2},\left(\mathrm{a}_{w}: 0.328\right), \mathrm{MgNO}_{3}\right)\left(\mathrm{a}_{w}: 0.529\right), \mathrm{NaBr}$ $\left(\mathrm{a}_{w}: 0.576\right), \mathrm{CoCl}_{2}\left(\mathrm{a}_{w}: 0.649\right), \mathrm{Na}_{2} \mathrm{NO}_{3},\left(\mathrm{a}_{w}\right.$ : $0.743), \mathrm{NaCl},\left(\mathrm{a}_{w}: 0.753\right)$ and $\mathrm{KCl}\left(\mathrm{a}_{w}: 0.843\right)$ (Greenspan, 1977). Once a constant weight was reached (after approximately 20 days), the moisture content was determined.

Experimental values were fitted to two different models: GAB (Guggenhein, Anderson and De Boer) and Halsey (Equations 1 and 2). The GAB model is the most commonly used for foodstuffs, while the Halsey model fitted well to processed teas from India (Ghodake, Goswami, \& Chakraverty, 2007).

$$
X=\frac{\left(X_{m} c k a_{w}\right)}{\left(\left(1-k a_{w}\right)\left(1-k a_{w}+c k a_{w}\right)\right)}
$$

where $X$ is the moisture content (g/100 of dry matter), $X_{m}$ is the monolayer moisture content $\left(\mathrm{g} / 100 \mathrm{~g}\right.$ of dry matter), $a_{w}$ is the water activity, $c$ is a constant related to heat of sorption of the first layer, and $k$ is a factor related to heat of sorption of the multilayer.

$$
a_{w}=e^{-\frac{a_{1}}{X^{r}}}
$$

where $a_{1}$ and $r$ are food and temperature dependent constants.

\subsection{Moisture content}

Moisture content was determined by drying the sample in an oven at $103 \pm 2^{\circ} \mathrm{C}$ until a constant weight was (ISO 1573, 1981). Three replicates were performed for each sample. An AND Code ER-180A balance $( \pm 0.0001 \mathrm{~g})$ was used.

\section{$2.9 \quad$ Statistical analysis}

Statistical analyses were conducted using Statgraphics Centurion (2009 version). Data were expressed as the mean values of duplicated tests \pm standard deviation of the mean. A one way ANOVA was used to evaluate the significance of results. For variables for which significant differences ( $p \leq 0.05$ ) were found, Fisher's least significant difference (LSD) was used for comparison of means.

\section{Results and Discussion}

\subsection{Water extract}

The water extract of tea consists of phenolic compounds, sugars, amino acids and many minor soluble substances, such as minerals and pigments (Yao et al., 2006).In this study, the water extract of twenty eight black teas ranged from $29.5 \%$ to $47.1 \%(\mathrm{w} / \mathrm{w})$, with a mean of $40.3 \%$ of the dry mass (Table 1). Water extract in tea should be greater than or equal to $32 \%$ of the dry mass (ISO 3720, 2011; ISO 11287, 2011). The water extract of two of the 28 samples of black tea did not meet this international standard. Compared with the water extract of black teas from other countries (Yao et al., 2006), China: 36.8\%, India: 36.9$41.9 \%$, Sri Lank: $36.7-46.9 \%$ and Kenya $44.1 \%$, the mean content of water extract of Argentine black teas is similar.

The water extract of 11 green teas ranged from $32.7 \%$ to $48.7 \%$ (w/w), with a mean of $40.7 \%$ of the dry mass (Table 1), all meeting the international basic requirement.

The water extract of eleven BTSP samples showed an average of $33.3 \%(\mathrm{w} / \mathrm{w})$ (Table 1 ), which is considerably lower than the water extract content found in black and green tea samples $(\mathrm{p}<0.05)$ (Figure 1). This off grade tea is of very low quality, composed of fibre and fluff from tea, so that these results were expected.

The marked variations observed in the water extract among samples of the same tea type could be attributed to different qualities of raw material used in the manufacture of each tea. 
(A)

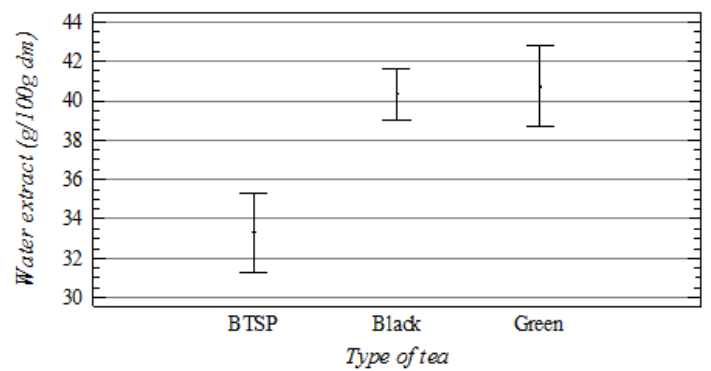

(B)

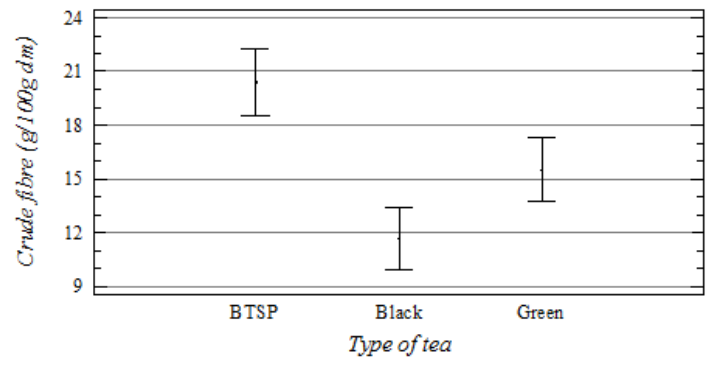

(C)

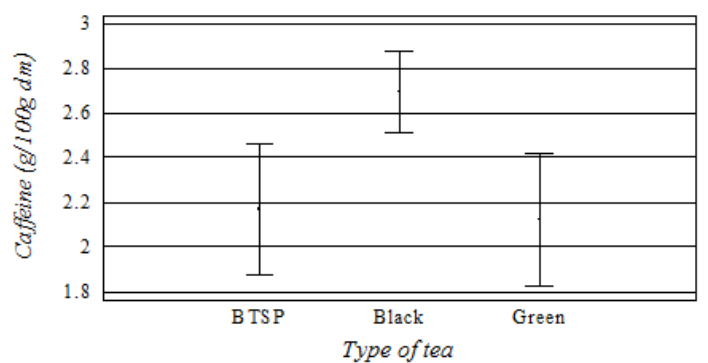

Figure 1: Physicochemical properties of the different types of tea. Water extract (A), Crude fibre (B) and caffeine (C) content.

\subsection{Crude fibre}

Crude fibre consists largely of cellulose, hemicellulose and lignin found in the cell walls of plants. Young cells have thin cellular walls that become harder as the plant grows and provide the plant with protection from wind, excess transpiration and influence of other undesirable factors (Smiechowska \& Dmowski, 2006).

One of the parameters described in tea quality norms is crude fibre content. Quality requirements for black and green tea state that crude fibre content should not exceed $16.5 \%$ (ISO 3720 ,
2011 (E), ISO 11287, 2011 (E)).

The crude fibre content of black tea samples ranged from $8.9 \%$ to $14.1 \%$ (w/w), with an average of $11.7 \%(\mathrm{w} / \mathrm{w})$ (Table 1$)$. In previous work (Smiechowska \& Dmowski, 2006) studied the crude fibre content of black tea from different countries. They reported that Chinese tea contained $11.5 \%$ crude fibre, whereas crude fibre in tea samples from India and Malawi were $15.2 \%$ and $21.1 \%(\mathrm{w} / \mathrm{w})$, respectively.

The crude fibre content of green tea samples varied between $10.8 \%$ and $20.5 \%$ (w/w), with a mean of $15.6 \%$ of the dry mass (Table 1 ). Four of the 11 green tea samples examined in this work did not meet the international standard.

The content of crude fibre in BTSP samples ranged very dramatically from $13.2 \%$ to $32.8 \%$ (w/w) (Table 1) being significantly higher than the values found in black and green tea samples (Figure 1).

The content of crude fibre in young tea leaves is much less than in older ones. High fibre content in the product may show that lower quality material has been used in the production $\left(5^{t h}-6^{t h}\right.$ leaf), or a careless, mechanical harvest of tea, when the yield contains not only leaves but also stems (Smiechowska \& Dmowski, 2006).

\subsection{Caffeine}

The caffeine content of 28 black tea samples ranged considerably from $1.0 \%$ to $3.6 \%(\mathrm{w} / \mathrm{w})$, with a mean of $2.7 \%(\mathrm{w} / \mathrm{w})$ (Table 1$)$. Earlier studies reported the caffeine content of black teas from a variety of origins ranged between $2.6 \%$ and $3.9 \%(\mathrm{w} / \mathrm{w})$ (Yao et al., 2006; Astill, Birch, Dacombe, Humphrey, \& Martin, 2001; Fernández, Martín, González, \& Pablos, 2000; Khokhar \& Magnusdottir, 2002).

The caffeine content of 11 green tea samples averaged at $2.1 \%(\mathrm{w} / \mathrm{w})$ (Table 1$)$, which is significantly lower than the average value found in black tea samples, as discussed earlier (Figure 1). Other authors reported caffeine contents ranging between 1.5 and $3.8 \%(\mathrm{w} / \mathrm{w})$ in green teas from different countries (Fernández et al., 2000; Astill et al., 2001; Yao et al., 2006; Khokhar \& Magnusdottir, 2002)).

Some studies reported lower caffeine concentra- 
Table 1: Water extract, crude fibre and caffeine content in the different types of tea.

\begin{tabular}{|c|c|c|c|c|c|c|c|c|c|c|}
\hline \multirow[t]{2}{*}{ Type of tea } & \multicolumn{3}{|c|}{$\begin{array}{l}\text { Water extract } \\
(\mathrm{g} / 100 \mathrm{~g} \mathrm{dm})\end{array}$} & \multicolumn{3}{|c|}{$\begin{array}{c}\text { Crude fibre } \\
(\mathrm{g} / 100 \mathrm{~g} \mathrm{dm})\end{array}$} & \multicolumn{3}{|c|}{$\begin{array}{c}\text { Caffeine } \\
(\mathrm{g} / 100 \mathrm{~g} \mathrm{dm})\end{array}$} & $n$ \\
\hline & Min & Max & $\mathrm{MV} \pm \mathrm{SD}$ & Min & Max & $\mathrm{MV} \pm \mathrm{SD}$ & Min & Max & $\mathrm{MV} \pm \mathrm{SD}$ & \\
\hline Black & 29.5 & 47.1 & $40.3 \pm 4.5$ & 8.9 & 14.1 & $11.7 \pm 1.7$ & 1.0 & 3.6 & $2.7 \pm 0.8$ & 28 \\
\hline Gree & 32.7 & 48.7 & $40.7 \pm 5.4$ & 1.8 & 20.5 & $15.5 \pm 3.0$ & 1.1 & 2.8 & $2.1 \pm 0.6$ & 11 \\
\hline BTSP & 23.4 & 40.1 & $33.3 \pm 4.7$ & 1.2 & 32.8 & $20.4 \pm 6.3$ & 1.4 & 3.0 & $2.2 \pm 0.5$ & 11 \\
\hline
\end{tabular}

Min: minimum.

Max: maximum.

$\mathrm{MV} \pm \mathrm{SD}:$ mean value \pm standard deviation.

$\mathrm{N}$ : number of samples.

BTSP: black tea sub-product.

tions in green tea than in black tea (Khokhar \& Magnusdottir, 2002; Lin, Tsai, Tsay, \& Lin, 2003). Schmalko and Alzamora (2001) reported a loss of caffeine of about $8 \%$ after blanching during the yerba mate manufacturing process, which is similar to the manufacturing process of green tea. This loss could be attributed to thermal degradation of the compound and a combined diffusion/evaporation mechanism.

However, other studies have demonstrated that caffeine content in green tea is higher when the starting material was the same because it was likely to be degraded during the tea fermentation process (Astill et al., 2001; Kim et al., 2011).

Moreover, it should be noted that caffeine content varies widely due to factors such as tea clone, geographical location, harvest time, leaf age and leaf quality (Yao et al., 2006; Kim et al., 2011). Thus, the reason why black tea was found to contain more caffeine than green tea in the present paper might be attributable to these factors.

The caffeine content of 11 BTSP samples showed an average of $2.2 \%(\mathrm{w} / \mathrm{w})$ (Table 1$)$. This result is in agreement with the fact that BTSP is mainly composed of fibrous residues of old tea leaves and stems.

\subsection{Total polyphenols content and antioxidant activity}

It has been demonstrated that polyphenols are the most abundant group of constituents in the tea leaf. Among these, the catechins constitute the major component of fresh tea leaves, and their concentration is remarkably higher in young tea leaves than in older ones (Lin et al., 1998).

The phenolic compounds that are present in tea leaves are known to be one of the main factors in determining the quality of the resulting drink (Yao et al., 2005). According to international standards (ISO 3720, 2011; ISO 11287, 2011) the TPC in black tea should be greater than or equal to $9 \%$ of the dry mass, and the TPC in green tea should be greater than or equal to $11 \%$ of the dry mass.

As shown in Table 2 the TPC in green tea samples varied between 12.9 and $16.1 \mathrm{~g}$ GAE/100 $\mathrm{g}$ and it was significantly lower (9.5-13.3 g GAE/100 g) in black tea samples $(\mathrm{p}<0.05)$ (Figure 2). These results are consistent with those of Astill et al. (2001), Anesini et al. (2008), Kim et al. (2011) who reported that the level of total polyphenols was higher in green tea than in black tea.

Catechins remain relatively intact during green tea manufacturing process. This is because freshly plucked tea leaves are immediately steamed or pan-fired to inactivate polyphenol oxidase. Black tea production, on the other hand, involves a leaf disruption step promoting the enzymatic oxidation of catechins to produce polymeric flavonoids (theaflavins and thearubigins) 
174 |Thea, Ana E. et.al.

Table 2: Total polyphenol content (TPC) and antioxidant activity (AOA) in the different types of tea.

\begin{tabular}{lccccccc}
\hline & \multicolumn{3}{c}{$T P C$} & \multicolumn{4}{c}{$A O A$} \\
Type of tea & \multicolumn{2}{c}{$(g$ GAE $/ 100 \mathrm{gdm})$} & \multicolumn{4}{c}{$(g A A E / 100 \mathrm{~g} d m)$} & $n$ \\
\cline { 2 - 8 } & Min & Max & MV $\pm \mathrm{SD}$ & Min & Max & MV $\pm \mathrm{SD}$ & \\
\hline Black & 9.5 & 13.3 & $11.1 \pm 0.8$ & 20.8 & 23.5 & $22.0 \pm 1.1$ & 7 \\
Green & 12.9 & 16.1 & $14.9 \pm 0.6$ & 26.1 & 35.3 & $30.0 \pm 1.2$ & 5 \\
BTSP & 8.3 & 9.6 & $8.6 \pm 0.6$ & 16.0 & 18.5 & $17.4 \pm 1.2$ & 5 \\
\hline
\end{tabular}

Min: minimum.

Max: maximum.

$\mathrm{MV} \pm \mathrm{SD}:$ mean value \pm standard deviation.

$\mathrm{N}$ : number of samples.

BTSP: black tea sub-product.

(Lin et al., 1998; Astill et al., 2001; Gramza \& Korczak, 2005; Muthumani \& Kumar, 2007; Kim et al., 2011; Kerio et al., 2012). Nevertheless, partial polymerization and other alterations occurring during black tea fermentation do not diminish its antioxidant capacity (Luczaj \& Skrzydlewska, 2005). The Folin-Ciocalteau assay is a common method to determine the amount of phenolic compounds by measuring their reducing capacity, based on the chemical oxidation of the reduced molecules by two inorganic oxidants phosphotungstic and phosphomolybdic acids. The differences in TPC between black and green tea could be attributed to differences in the content of non-phenolic reducing molecules between them or differences in Folin-Ciocalteau response to the green tea polyphenols (mainly monomeric polyphenols) and black tea polyphenols (mainly multimeric polyphenols) (Astill et al., 2001; Kim et al., 2011).

The AOA of black tea samples ranged between 20.8 and $23.5 \mathrm{~g} \mathrm{AAE} / 100 \mathrm{~g}$ and it was significantly lower than the values found in green tea samples $(\mathrm{p}<0.05)(26.1-35.3 \mathrm{~g}$ AAE/100 g) (Figure 2). Previous studies have also reported these results (Anesini et al., 2008; Kim et al., 2011; von Staszewski et al., 2011). It was found that the AOA of black tea polyphenols (theaflavins and thearubigins) are considerably lower than the AOA of catechins mainly present in green tea (Gramza \& Korczak, 2005). In spite of this, other authors found that theaflavins show comparable antioxidant capacity with epigallocate-
(A)

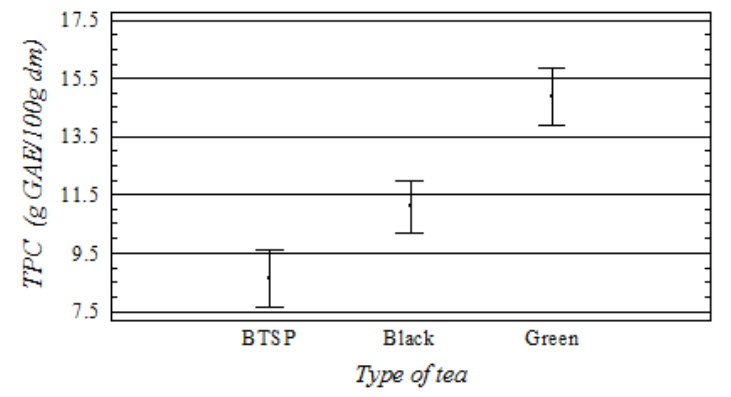

(B)

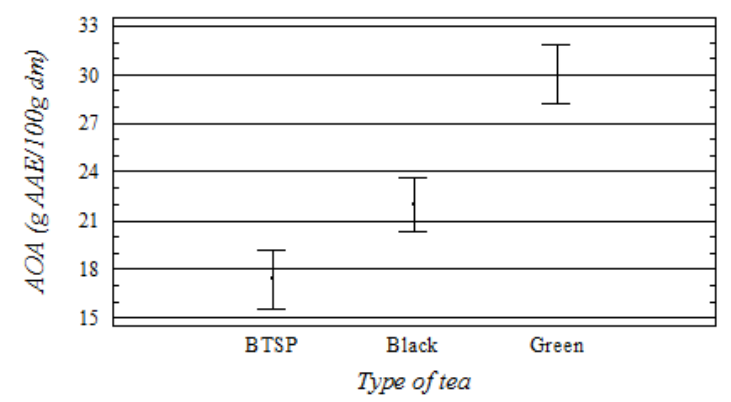

Figure 2: Total polyphenol content (A) and antioxidant activity (B) of the different types of tea.

chin gallate, which is the most abundant catechin in green tea, and a higher radical scavenging activity than other green tea catechins (epicatechin, epigallocatechin and epicatechin gallate) (Luczaj \& Skrzydlewska, 2005; Karori, Wachira, Wanyoko, \& Ngure, 2007; Kim et al., 2011). Kim

IJFS | October 2012 | Volume 1 | pages 168-178 
et al. (2011) stated that the difference in AOA could be not only caused by the difference in concentrations of green and black tea polyphenolics in each tea, but also because of the decline in other antioxidants such as flavonol glycosides, caffeine, saponine and ascorbic acid during the fermentation process.

As shown in Table 2 the lowest values of TPC and AOA were found in BTSP samples (8.3-9.6 g GAE/100 g and 16-18.5 g AAE/100 g, respectively).

\subsection{Colour}

During the fermentation, tea leaves change colour from dark green to coppery brown. As shown in Table 3, the L (darkness to lightness) value was significantly lower in black tea than in green tea $(\mathrm{p}<0.05)$. This is because tea becomes darker during oxidation due to the increase in thearubigins (Muthumani \& Kumar, 2007; Kim et al., 2011). The intermediate $L$ value found in BTSP samples is due to high fibre content that provides lightness to this fully fermented product.

The other colour parameters, a (green to red) and $\mathrm{b}$ (yellow to blue), were different according to the type of tea (Table 3). Variation in these colour values are mainly caused by higher theaflavin concentration in fermented teas that gives the product yellow, orange and red colours (Kim et al., 2011).

\subsection{Adsorption isotherms}

The moisture content at different $\mathrm{a}_{w}$ values had, in all cases, coefficients of variation less than $5 \%$. Figure 3 shows adsorption isotherms for the different types of tea at $25^{\circ} \mathrm{C}$. Green and black tea showed no differences in their moisture content at all $\mathrm{a}_{w}$ values. BTSP had minor moisture contents than green and black tea until $\mathrm{a}_{w}=0.753$, but then all showed similar moisture sorption behaviours.

Among the sorption models tested, the best fit was obtained using Halsey model $(\mathrm{p}<0.0001)$; per cent errors minor than $4 \%$ between experimental data and model predictions were found. Constant values for this model were similar to

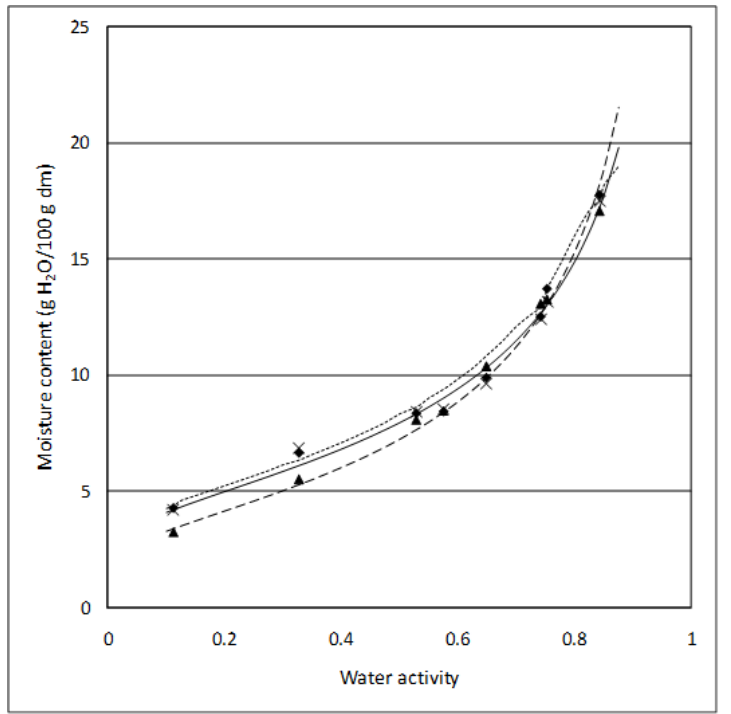

Figure 3: Adsorption isotherms of the different types of tea. Experimental (exp) and theoretical (theo) values calculated with Halsey equation: Black tea exp __ Black tea theo X Green tea exp - - - - - Green tea theo $\triangle$ Black tea sub-product exp _ _ _ Black tea sub-product theo.

those obtained by Ghodake et al. (2007) in Indian tea. Moisture content for aw $=0.6$ were similar in black tea $(9.44 \% \mathrm{w} / \mathrm{w})$; green tea $(9.41 \%$ $\mathrm{w} / \mathrm{w})$ and BTSP $(8.85 \% \mathrm{w} / \mathrm{w})$. These differences are too small in order to establish different critical moisture contents for different types of tea. Argentine Food Code (2011) states that moisture content of teas in general should not exceed $7.5 \%$ of the dry matter.

\subsection{Semifermented tea}

Quality parameters were analyzed in the only semifermented tea produced in Argentina and the results are presented in Table 4 . The caffeine content $(1.6 \% \mathrm{w} / \mathrm{w})$ of semifermented tea was lower than the mean content detected in BTSP, green and black tea samples. Water extract $(32.9 \% \mathrm{w} / \mathrm{w})$ and crude fibre $(22.3 \% \mathrm{w} / \mathrm{w})$ contents, TPC (8.9 g GAE/100 g dm) and AOA (17.6 g EAA/100 g dm) of semifermented tea were similar to those found in BTSP samples. Colour values (L, a, b) were also comparable to 
$176 \mid$ Thea, Ana E. et.al.

Table 3: Colour parameters of the different types of tea (Mean value \pm standard deviation)

\begin{tabular}{lcccc}
\hline Type of tea & $L$ & $a$ & $b$ & $n$ \\
\hline Black & $24.8 \pm 2.2$ & $2.9 \pm 1.1$ & $9.8 \pm 2.7$ & 28 \\
Green & $37.1 \pm 4.8$ & $-1.1 \pm 2.1$ & $2.5 \pm 4.6$ & 11 \\
BTSP & $32.9 \pm 4.3$ & $5.0 \pm 1.1$ & $16.4 \pm 2.6$ & 11 \\
\hline
\end{tabular}

$\mathrm{N}$ : number of samples.

BTSP: black tea sub-product.

Table 4: Quality parameter values of Argentinean semifermented tea*.

\begin{tabular}{lr}
\hline Quality parameters & \\
\hline Water extract $(g / 100 \mathrm{~g} \mathrm{dm})$ & 32.9 \\
Crude fibre $(g / 100 \mathrm{~g} \mathrm{dm})$ & 22.3 \\
Caffeine $(g / 100 \mathrm{~g} \mathrm{dm})$ & 1.6 \\
TPC $(g \mathrm{GAE} / 100 \mathrm{~g} \mathrm{dm})$ & 8.9 \\
AOA $(g A A E / 100 \mathrm{~g} \mathrm{dm})$ & 17.6 \\
Color & \\
\hline
\end{tabular}

$\mathrm{L}$

a

AOA: antioxidant activity.

TPC: total polyphenol content.

* Average of three determinations with CV less than $5 \%$.

the ones found in BTSP samples. These results suggest that a very low quality material has been used for its production.

\section{Conclusions}

Water extract contents of black and green tea were higher than those found in semifermented tea and BTSP. Semifermented tea and BTSP showed higher levels of crude fibre than black and green tea. Because of their different manufacturing processes TPC and AOA were different in each type of tea. Green tea showed the highest concentration of phenolic compounds, and the highest antioxidant capacity. Some previous reports have demonstrated that caffeine decreases during tea fermentation. Nevertheless, in the present research the highest caffeine content was found in black tea. This result could be due to many factors including those that are inherent in tea plant itself, geographical origin and horticultural practices.

Water extract and crude fibre measurements are useful for determining the quality of the material used in tea production. These quality parameters may be atypical as a result of excessive pruning or adulteration of tea with BTSP. The caffeine content, TPC and AOA not only reflect the hierarchy of the raw material used in the elaboration of tea but also quantify the biological properties of each product. Therefore, these assays should be implemented to tea quality control. Color values are very useful to differentiate between the different types of tea.

\section{References}

Anesini, C., Ferraro, G., \& Filip, R. (2008). Total polyphenol content and antioxidant capacity of commercially available tea (Camel- 
lia sinensis) in Argentina. Journal of Agricultural and Food Chemistry, 56(19), 92259229. doi: $\{10.1021 / \mathrm{jf8022782 \}}$

Astill, C, Birch, M., Dacombe, C, Humphrey, P., \& Martin, P. (2001). Factors affecting the caffeine and polyphenol contents of black and green tea infusions. Journal of Agricultural and Food Chemistry, $49(11)$, 53405347. doi: $\{10.1021 /$ jf010759+\}

FAO Statistics Division. (2011). Accessed: May 5, 2011, Retrieved from http: / / faostat. fao . org / site / 567 / DesktopDefault . aspx? PageID $=567 \#$ ancor

Fernández, P., Martín, M., González, A., \& Pablos, F. (2000). HPLC determination of catechins and caffeine in tea. Differentiation of green, black and instant teas. Analyst, 125(3), 421-425. doi:\{10.1039/a909219f \}

Ghodake, H. M., Goswami, T. K., \& Chakraverty, A. (2007). Moisture sorption isotherms, heat of sorption and vaporization of withered leaves, black and green tea. Journal of Food Engineering, 78(3), 827835. doi:\{10.1016/j.jfoodeng.2005.11.023\}

Gramza, A, \& Korczak, J. (2005). Tea constituents (Camellia sinensis L.) as antioxidants in lipid systems. Trends in Food Science \& Technology, 16(8), 351-358. doi:\{10.1016/j.tifs.2005.02.004\}

Greenspan, L. (1977). Humidity Fixed-Points of Binary Saturated Aqueous-Solutions. Journal of Research of The National Bureau of Standards Section A-Physics And Chemistry, 81(1), 89-96.

Hartwig, V. G., Brumovsky, L. A., Fretes, R. M., \& Sánchez Boado, L. (2012). A novel procedure to measure the antioxidant capacity of Yerba maté extracts. Ciência e Tecnologia de Alimentos, 32, 126 -133. doi:\{10.1590/ S0101-20612012005000022\}

ISO 10727. (2002). Tea and instant tea in solid form - Determination of caffeine content - Method using High Performance Liquid Chromatography.

ISO 11287. (2011). Green tea - Definition and basic requirements.

ISO 14502-1 (E). (2004). Determination of substances characteristic of green and black tea - Part 1: Content of total polyphenols in tea - Colorimetric method using FolinCiocalteu reagent.

ISO 15598. (1999). Tea - Determination of crude fibre content.

ISO 1573. (1981). Tea - Determination of loss in mass at $103^{\circ} \mathrm{C}$.

ISO 3720. (2011). Black tea - Definition and basic requirements.

ISO 9768. (1994). Tea - Determination of water extract.

Jayasekera, S., Molan, A. L., Garg, M., \& Moughan, P. J. (2011). Variation in antioxidant potential and total polyphenol content of fresh and fully-fermented Sri Lankan tea. Food Chemistry, 125(2), 536541. doi:\{10.1016/j.foodchem.2010.09.045\}

Karori, S. M., Wachira, F. N., Wanyoko, J. K., \& Ngure, R. M. (2007). Antioxidant capacity of different types of tea products. African Journal of Biotechnology, 6(19), 2287-2296.

Kerio, L., Wachira, F., Wanyoko, J., \& Rotich, M. (2012). Characterization of anthocyanins in Kenyan teas: Extraction and identification. Food Chemistry, 131(1), $31(8)$.

Khokhar, S, \& Magnusdottir, S. (2002). Total phenol, catechin, and caffeine contents of teas commonly consumed in the United Kingdom. Journal of Agricultural and Food Chemistry, 50(3), 565-570. doi:\{10.1021/ jf0101531\}

Kim, Y., Goodner, K. L., Park, J.-D., Choi, J., \& Talcott, S. T. (2011). Changes in antioxidant phytochemicals and volatile composition of Camellia sinensis by oxidation during tea fermentation. Food Chemistry, 129(4), 1331-1342. doi: $\{10.1016 / \mathrm{j}$. foodchem.2011.05.012\}

Lin, J., Lin, C., Liang, Y., Lin-Shiau, S., \& Juan, I. (1998). Survey of catechins, gallic acid, and methylxanthines in green, oolong, pu-erh, and black teas. Journal of Agricultural and Food Chemistry, 46(9), 36353642. doi: $\{10.1021 / \mathrm{jf9} 90223 \mathrm{x}\}$

Lin, Y., Tsai, Y., Tsay, J., \& Lin, J. (2003). Factors affecting the levels of tea polyphenols and caffeine in tea leaves. Journal of Agricultural and Food Chemistry, 51(7), 18641873. doi: $\{10.1021 / \mathrm{jf0} 21066 \mathrm{~b}\}$ 
Luczaj, W, \& Skrzydlewska, E. (2005). Antioxidative properties of black tea. Preventive Medicine, 40(6), 910-918. doi:\{10.1016/j. ypmed.2004.10.014\}

Muthumani, T., \& Kumar, R. S. S. (2007). Influence of fermentation time on the development of compounds responsible for quality in black tea. Food Chemistry, $101(1), 98$ 102. doi:\{10.1016/j.foodchem.2006.01.008\}

Parra, P. (2007). Secretaría de Agricultura, Ganadería, Pesca y Alimentos. Ministerio de Economía y Producción. Té (Camellia sinensis). Análisis de la cadena alimentaria. Accessed: November 7, 2011, Retrieved from http : / / www . alimentosargentinos . gov . ar / 0 - 3 / infusion / te - mayo - 2006 / infusiones_te.htm

Prat Kricun, S. D., \& De Bernardi, L. A. (2002). Secretaría de Agricultura, Ganadería, Pesca y Alimentos. Dirección Nacional de Alimentación. Ministerio de Economía y Producción. Cadena alimentaria del Té "Camellia sinensis". Diagnóstico del sector tealero. Accessed: November 7, 2011, Retrieved from http://www.itescam.edu.mx/ principal/sylabus / fpdb / recursos / r67179 . PDF

Ravichandran, R. (2004). The impact of pruning and time from pruning on quality and aroma constituents of black tea. Food Chemistry, 84(1), 7-11. doi: $\{10.1016 /$ S0308-8146(03)00159-6\}

Saito, S. T., Gosmann, G., Saffi, J., Presser, M., Richter, M., \& Bergold, A. (2007). Characterization of the constituents and antioxidant activity of Brazilian green tea ( Camellia sinensis var. assamica IAC- 259 Cultivar). extracts. Journal of Agricultural and Food Chemistry, 55, 9409-9414.

Schmalko, M., \& Alzamora, S. (2001). Color, chlorophyll, caffeine, and water content variation during yerba mate processing. Drying Technology, 19(3-4), 599-610. doi: $\{10.1081 / D R T-100103937\}$

Smiechowska, M, \& Dmowski, P. (2006). Crude fibre as a parameter in the quality evaluation of tea. Food Chemistry, 94(3), 366368. doi:\{10.1016/j.foodchem.2004.11.026\} von Staszewski, M., Pilosof, A. M. R., \& Jagus, R. J. (2011). Antioxidant and antimicrobial performance of different Argentinean green tea varieties as affected by whey proteins. Food Chemistry, 125(1), 186-192. doi:\{10. 1016/j.foodchem.2010.08.059\}

Yao, L., Liu, X, Jiang, Y., Caffin, N, D’Arcy, B, Singanusong, R, ... Xu, Y. (2006). Compositional analysis of teas from Australian supermarkets. Food Chemistry, 94 (1), 115122. doi: $\{10.1016 /$ j.foodchem.2004.11.009\}

Yao, L., Caffin, N, D’Arcy, B, Jiang, Y., Shi, J, Singanusong, R, ... Xu, Y. (2005). Seasonal variations of phenolic compounds in Australia-grown tea (Camellia sinensis). Journal of Agricultural and Food Chemistry, 53(16), 6477-6483. doi:\{10.1021/ jf050382y 